\title{
VOCABULARIOS Y GLOSARIOS DEL ESPAÑOL DE LOS SIGLOS XIV AL XVI*
}

\author{
Lidio NIETO
}

Instituto de la Lengua Española. CSIC

\begin{abstract}
Aunque podemos encontrar repetidas, no sin fundamento, las afirmaciones de que la historia de la lexicografía española está por hacer, no deja de ser cierto que, de un tiempo a esta parte, se observa una preocupación creciente en los investigadores por cubrir esta laguna. Basta echar una hojeada a las Actas de los últimos congresos relativos al dominio de la lengua, los programas universitarios de la especialidad, donde se incluye como materia la lexicografía, e incluso la producción editorial reciente, para constatar el crecimiento a que me refiero. Ahora bien, en el panorama docente se suele soslayar o prestar poca atención a lo que pudiéramos llamar "lexicografía menor", aunque esta expresión debiera matizarse, o mejor, para evitar precisiones, decir que se presta poca atención a todo aquello que no son los grandes diccionarios. Tampoco es habitual ocuparse de los aspectos temáticos, por más interés que éstos puedan ofrecer.

En las páginas que siguen me voy a centrar, de acuerdo con la acotación histórica que señalo arriba en el título, en los repertorios lexicográficos que pueden encontrarse al margen de los diccionarios considerados como tales o en todo caso de aquellos repertorios que aunque en sentido estricto pudieran definirse como diccionarios, por el hecho de aparecer formando parte de otra obra o ser reducidos en cuanto al número de entradas, no han merecido la atención que les corresponde en una verdadera historia de la lexicografia española.

Comenzaré mi análisis por los Glosarios Latino españoles de la Edad Media, título con el que Américo Castro recogió en 1936 tres glosarios: El Escorial, Palacio y Toledo, llamados así por el lugar en que se encontraron ${ }^{1}$.
\end{abstract}

\footnotetext{
* Este trabajo se inscribe en los programas de investigación PB95-0137-C02-01 y PB980671-C02-01 del Ministerio de Educación y Cultura.

${ }^{1}$ Existe una reedición actual de esta obra: Américo Castro, Glosarios Latino-Españoles de la Edad Media, Madrid, C.S.I.C., 1991.
}

RFE, LXXX, 2000, $1 .^{\circ}-2 .^{\circ}$, págs. $155-180$ 
Si bien no existe fecha segura para su datación, la letra de los manuscritos nos lleva a pensar que el de El Escorial y el de Toledo sean del siglo XIV $\mathrm{y}$ el de Palacio de principios del siglo XV.

Es cierto que estos glosarios son latino-españoles, pero me parece que son punto de referencia obligada en la historia de la lexicografia española, si no en sentido estricto (supuesto que concibiésemos esa historia unidireccionalmente, esto es, español otra lengua) sí al menos como prolegómenos y como base para valorar mejor la obra de otros lexicógrafos, entre ellos Alfonso Fdez. de Palencia y Nebrija.

La importancia de esta recopilación de Américo Castro se basa también en las pocas noticias de que disponemos sobre el latín medieval y en el gran desconocimiento de los textos de carácter lexicográfico. Es cierto que en su elaboración Don Américo se vio obligado a corregir y presuponer en más de una ocasión, lo que quiere decir que los listados, sus equivalencias, han de tomarse con cautela, pero es destacable saber que tenemos un corpus de no poca importancia, que se adelanta al menos en un siglo a los diccionarios de Palencia (1490) y Nebrija (1492) y que puede ayudarnos a entender de manera más crítica tanto el español como el latín usado en la Edad Media.

Es más que probable que en un análisis profundo de estos glosarios aparezca la filiación con los glosarios latinos que recoge el Corpus Glossariorum Latinorum de Goetz, aquellos que explicaban a los estudiantes el latín desde el latín, sustituidos más tarde por los latino-románicos, cuando ya el latín necesitaba del romance para ser entendido. Es también probable que la huella de la lexicografia medieval, especialmente de Papias (finales del siglo XI), Hugucio (finales del XII) y Juan Balbi (muerto en 1298) sea fácilmente reconocible. Y en línea más localista convendría no olvidar la tradición glosográfica de las Etymologias de San Isidoro. Pero mi objetivo en estos momento no es analizar los glosarios de que me ocupo, sino constatar su existencia y afirmar que las 6.128 palabras glosadas (incluidas algunas repeticiones) que en ellos se registran constituyen un importante acervo lexicográfico.

Según parece, los tres glosarios son de procedencia aragonesa, zona donde el latín notarial pervivió más que en Castilla. El de Toledo (T) fue descrito por C.E. Kany al hacer la edición de los Proverbios de Salomón que se encuentran también en el códice 99-37 de la Biblioteca de la Catedral de Toledo. Comienza en el folio 30r y acaba en el 50. Está escrito a dos columnas, según se puede comprobar en la página reproducida.

El de Palacio (P) se limita a dos folios que fueron encuadernados junto al Vocabulario de Papias (éste del siglo XIII) en un códice de la Biblioteca del Palacio Real.

El glosario de El Escorial (E) es el más amplio y cuidado de los tres. Según la descripción del P. Zarco: "57 hojas de papel, foliadas a lápiz, con 


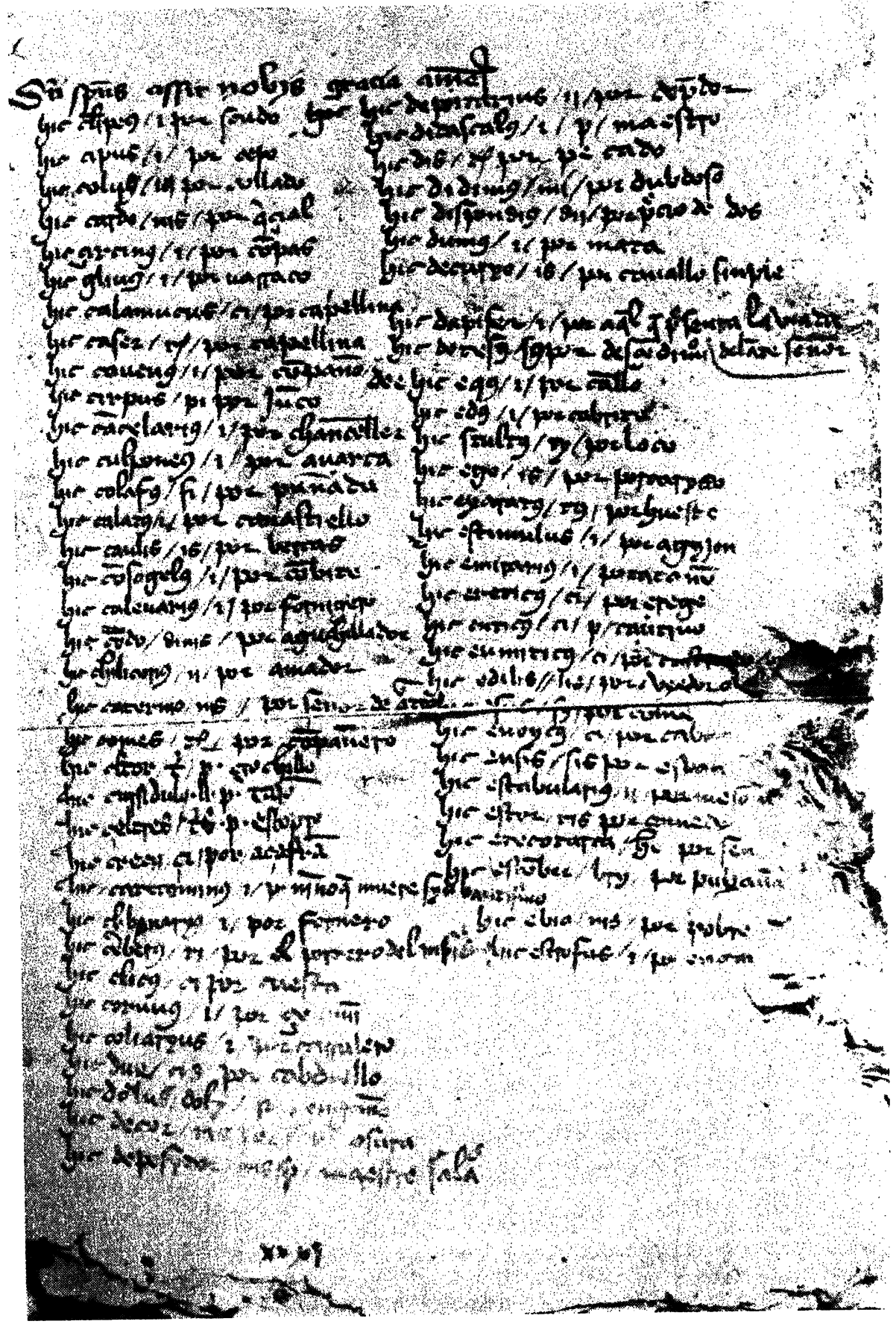

Fol. 2r del Glosario de Toledo. 
numeración arábiga, letra del siglo $\mathrm{XV}$ ". El ms. en que aparece se titula: $L i$ bro de adverbios, nombres, verbos y refranes latinos, con sus correspondientes españoles y la disposición de las glosas o equivalencia responde a una sola columna por página.

El segundo repertorio que en orden histórico yo mencionaría es el conservado en un ms. de la Biblioteca de la Real Academia de la Historia de Madrid $^{2}$. Se trata de un listado ("razonamiento", según el propio texto) de 152 voces castellanas, recogidas entre los folios $1 \mathrm{r}-35 \mathrm{v}$, muchas de ellas relativas a la milicia, tipo hueste, real, zelada:

"Hueste dizen en Castilla por toda la gente de armas y de guerra que los reyes y prínçipes llenan en sus conquistas y guerras; y es palabra latina de $<H>O S T I S$ que quiere deçir «enemigo» por que van contra sus enemigos y contra ellos hazen actos de enemigos".

"Real dizen en Castilla quando la hueste del rey esta asentada en el campo o sobre alguna çibdad; y toma el nombre de el rey que esta allí, que común mente a todos los actos y lugares de los reyes deçimos reales; antigua mente deçían «fosados» y tomaua el nombre de «fosa» que quiere en latín deçir "caua», que a los reales porque sean más seguros de los insultos de los enemigos fázenles cauas y aun palenques".

"Zeladas dizen en Castilla, y es vna de las artes de la guerra y es allí donde ponen gente de Armas en cubrirla, porque los enemigos saliendo apriesa y mal hordenados cayan en ellas y porque estas zeladas siempre se ponen en valles y en sotos. Dizen celada que es palabra latina que quiere deçir escondida o encubierta; en Ytalia y en Françia llaman enboscadas de bosques que dizen ellos por los montes".

Aunque hay otras de carácter general, mesón, morada, vergel:

"Mesón vocablo latino es, que dize mansion porque es lugar donde los caminantes y trabajadores descansan y reposan de sus trabajos y caminos. Que manere quiere deçir «estar» o «reposar» [...]".

"Moradas dizen los castellanos por las casas en que el hombre faze su prinçipal y continua biuienda. $\mathrm{Y}$ es vocablo latino que dize mora por «tardanza». Que todo hombre según su voluntad y deseo, salua la disposiçión de dios, allí propone y hordena de hazer la mayor parte de su vida; y pruéuase ésto por vna tal diferençia, que quando hombre va en la corte de el rey las casas que le dan donde pose no las llaman moradas, mas posadas que es como vna pausa o posada, que haze hombre por ellas, mas la tardanza en la morada se haze".

\footnotetext{
${ }^{2}$ Manuscrito núm. 73 (12-7-2) de la colección Salazar y Castro de la Real Academia de la Historia [Vocablos dificiles del castellano]. El original de este manuscrito pertenece al siglo XV, aunque la copia conservada parece del siglo XVI. Fue estudiado, primero, por Miguel Artigas, más tarde por Fernando Huarte Morton, RFE, 1951, XXXV, págs. 310-340, y final y más acertadamente por Tomás González Rolán y Pilar Saquero Suárez-Somonte. La transcripción de estos últimos (Latín y castellano, Madrid, Ediciones clásicas, 1995, págs. 86-171) es la que sigo.
} 
"Vergeles y jardines dizen en otros reynos; en Castilla y Portogal dizen huertas. Y a mi ver es mas proprio vocablo y mas çerca de el latín que dizen ortus, por «nasçimiento» y en la huerta continua mente naçen nueuas cosas así como frutas, flores y ortalizas. No se sigue que por ser vn vocablo más llegado al latín sea mejor, como nota Baldasar Castellón al prinçipio de El Cortesano."

En todo caso y al margen de otras cuestiones de teoría lingüística, como pueden ser el origen del español o la defensa de la alteratio, en cuanto a criterio de evolución, yo destacaría el espíritu que alienta el primero de los 35 folios que integran el texto que nos interesa: "Así es que muchos vocablos de la lengua castellana pareçen a los extrangeros impropios y tales que no tienen algún fundamento razonable, lo qual vienen por culpa o defecto de los que mal y torpe mente los pronunçian corrompiendo y dañando la propiedad de los vocablos, y corrupta la propiedad piérdese la significacion de ellos y biene esto por la mayor parte por la groseza y rustiçidad de los aldeanos cuya torpedad y rudeza es enemiga y madrastra de la fermosa eloquençia y poliçia de el hablar..." cablos es la justificación fundamental de este listado.

Antes de entrar en el tercero de los repertorios que desde un punto de vista histórico tengo identificados, me parece conveniente aludir a un listado de voces, importante en sí mismo, puesto que recoge alrededor de 24.000 formas, cantidad destacable comparándola con los repertorios léxicos del momento, pero que desde mi punto de vista no debe ser incluido en un inventario de trabajos lexicográficos, puesto que carece de uno de los requisitos fundamentales que cabe exigir a éstos: la intencionalidad informativa semántica, bien mediante definiciones y explicaciones o mediante términos equivalentes en la propia lengua $u$ otra diferente; tampoco tenemos ordenación del léxico recogido que obedezca a criterios lexicográficos. $\mathrm{Y}$ es que La Gaya Ciencia ${ }^{4}$ o, para ser más precisos, el Rimario, que es la parte más importante de la misma, es un repertorio de voces españolas agrupadas por la terminación a partir de la vocal tónica, en función del número de sílabas. Pueden encontrarse variantes morfológicas debidas tanto a la conjugación como a la flexión nominal y algunos nombres propios. Sin duda, se trata de un texto importante, que se anticipa no poco a obras como el Arte poética española de Juan Díaz de Rengifo y enlaza con la tradición medieval trovadoresca, pero no es una obra lexicográfica en sentido estricto.

Sí lo es, a pesar de la brevedad, el listado de voces que encontramos en las once últimas páginas de la primera edición de las Introductiones latinae

${ }^{3}$ Latín y castellano, pág. 80.

${ }^{4}$ Pero Guillén de Segovia, La Gaya Ciencia, edic. de O. J. Tuulio, Madrid, C.S.I.C., 1962. 
de Nebrija ${ }^{5}$. No voy a descrubrir a estas alturas ni la importancia ni el interés de la obra del catedrático salmantino. Pero sí quisiera insistir sobre algo que ya en 1946 dijo Armando Cotarelo Valledor ${ }^{6}$ en la semana nebrisense de Sevilla: que el Nebrija científico o, mejor, humanista, le empuja a abordar los más diversos saberes y que éstos, en el campo lexicográfico, van más allá del Dictionarium latino-hispanicum y el Vocabulario de romance en latín; hay, de hecho, dos repertorios lexicográficos que bien pudieran considerarse antecedentes de los grandes diccionarios que acabo de mencionar. Me refiero a los vocabularios que se encuentran en la primera y segunda edición de sus Introductiones latinae.

El primero de los vocabularios aparece, como he dicho antes, en las últimas páginas de la obra (f. . $^{\circ}$ i y sgtes., sin encabezamiento especial), para explicar algunos términos usados a lo largo del texto, probablemente porque como apuntó F. Rico las Introductiones son apenas "un manual de latín para muchachos". Son en total 158 voces castellanas las que registra Nebrija como equivalentes de otras latinas. Hay que aclarar que no todos los términos latinos recogidos en el vocabulario (aunque sí la mayoría) se explican mediante equivalentes castellanos; así, mientras hay entradas del tipo: abigere est oxear o arredrar; acicula, vulgo el alfiler, tenemos otras como absolvere est perficere; abdicare est filium a bonis expellere.

El segundo de los vocabularios aparece en la segunda redacción de las Institutiones latinae, publicada en 1485, con dedicatoria a Gutierre de Toledo, Rector de Salamanca. Hay, al menos, tres reimpresiones de esta segunda versión: Venecia (Cristóbal de Cremona, 1491) y Burgos (Fadrique de Basilia, 1493 y 1495). El texto de esta segunda versión es el punto de partida para la edición bilingüe, que no debe ser anterior a 1487 (según Rico, 1488), si bien no aparece en esta versión el vocabulario a que me estoy refiriendo, probablemente porque Nebrija lo juzgó innecesario al estar el texto en castellano. Sí vuelve a encontrarse en la llamada Recognitio (Salamanca, 1495), tercera edición y versión definitiva, de donde parten la mayoría de las ediciones posteriores, entre ellas las catalanas, que siguen contando con el vocabulario, bien es verdad que notablemente diferenciado de unas ediciones a otras ${ }^{7}$.

\footnotetext{
${ }^{5}$ Como se recordará, esta primera versión de las Introductiones tuvo tres ediciones, todas ellas salmantinas: la de 16 de enero de 1481 , la de 13 de octubre de 1482 (ejemplar en la Biblioteca Pública de Toledo, Códice I/32) y la de 5 julio de 1483 (ejemplar en Biblioteca de San Marino, California). Modernamente, se hizo un facsímil, editado por la Universidad de Salamanca, Salamanca, 1981.

${ }^{6}$ Nebrija Científico, R.A.H., Publicaciones del Instituto de España, Madrid, 1947.

7 Germán Colón constata que ya en la primera de estas ediciones (Joan Rosenbach, Barcelona, 1497) se recoge el vocabulario. Lo mismo debió ocurrir en la edición de 1501 (Joan Luschner, Barcelona), aunque la mutilación de las últimas páginas del único ejemplar exis-
} 
Centrándonos en el vocabulario o, mejor, los vocabularios, puesto que en realidad son dos, aunque no aparecen en todas las ediciones de las Introductiones, hay que decir que el primero de ellos: Dictiones que per artem sparguntur in ordinem alphabetarium redactae tiene un total de 1993 correspondencias castellanas, suprimidos ya los nombres propios. El repertorio se ordena alfabéticamente, a partir del latín, tipo accipiter, tris, el gavilán, açor o halcón, y recoge todo tipo de palabras.

El segundo, denominado Paruum vocabularium, cuya primera constatación no he podido documentar antes de la edición zaragozana de G. Coci, $1525^{8}$, si bien Julián Martín $\mathrm{Abad}^{9}$ estima que puede anticiparse hasta la edición complutense de las Pueriles Introductiones de 1518, es un repertorio temático con trece apartados, señalados al comienzo del mismo, a modo de índice, y un total de 859 voces romances. Es un buen antecedente de los diccionarios ideológicos.

El conjunto de los dos vocabularios (aunque hay algunas voces que se repiten en uno y otro) representa casi un treinta por ciento de las entradas que aparecen en el Vocabulario de romance en latín, lo que justifica sobradamente que no puedan marginarse estos repertorios al analizar la labor lexicográfica de Nebrija. Y en esta misma línea, aunque sea adelantarnos a lo que después veremos con más detalle, habría que inscribir su Latina vocabula ex iure ciuili in uoces hispanienses interpretata y el amplio listado de voces técnicas que está en la edición del Dioscórides (Alcalá, 1518).

tente no nos permitan asegurarlo ni saber si ya habían sido sustituidas por voces catalanas los términos romances equivalentes de los latinos, como es seguro que ocurrió a partir de las ediciones de 1505 (véase Germán Colón, Prólogo a la edición del diccionario de Nebrija, págs. 14 y 15$)$.

Para nuestros fines parto del ejemplar de la edición salmantina del 30 de septiembre de 1495, Complutense Noviciado, sig. I335.

8 Manejo el ejemplar de la B.N. R/31422. En esta edición, al igual que en la también zaragozana de Pedro Berauz, 1558 (B.N. R/2228) aparece el Paruum Vocabularium, pero no así en las de Arnao Guillén de Brocar (Logroño 1503, 1508 y 1513, representadas en los ejemplares de la B.N. de Madrid R/7688, R/4775, R/31571), ni en las alcalaínas de Miguel de Eguía de 1525 y 1530 (B.N., U/11136 y R/28552, respectivamente), ni en la sevillana de Juan Pegnigzer de Nurember y Magno Herbst, de 1502 (B.N., R/8538) que, como se sabe, es el punto inmediato de enlace de la edición logroñesa de Brocar de 1503 con la Recognitio salmantina de 1495. Es claro, pues, que el Paruum vocabularium hay que rastrearlo a partir de la edición zaragozana de Coci.

9 "Conviene señalar - afirma - que la tan repetida edición de las Pueriles introductiones del 18 de septiembre de 1518 , siempre de acuerdo con el contenido que se ofrece en la edición zaragozana del 31 de agosto de 1525 , que anuncia seguirla, incluía otros dos textos de interés: un "Lexicon seu paruum uocabularium in quo breuiter invenies vocabula scolasticis valde necessaria» y...". ("Nebrija en los talleres de Arnao Guillén de Brocar y Miguel de Eguía", en Actas del Congreso Internacional de Historiografia Lingüistica, Nebrija V Centenario, Murcia, Universidad de Murcia, 1994, vol. I, pág. 43.). De esta edición complutense de 1518 sólo se conocen las cuatro hojas finales. 
Un antecedente más de los grandes diccionarios: el que se encuentra entre los folios 90r-104v de la Breuis grammática ${ }^{10}$ de Andrés Gutiérrez Cerezo (Fadrique de Basilia, Burgos, 1485), bajo el título Totius opusculi significationes uocabulorum secundum ordinem alphabeti digestae hae fere sunt. Es evidente que en este elenco el discípulo nebrisense sigue al maestro en el método, aunque su nómina de cerca de 1.500 voces se refiera más al latín que al castellano (poco más del $15 \%$ del total). Las explicaciones tienen, en general, carácter enciclopédico, salvo cuando se dan equivalentes españoles, cosa que ocurre en 231 ocasiones (adipisci, ganar, alcançar; ascribere, imputar; asertor, defendedor o vengador, etc.). El léxico registrado es de carácter general, aunque abundan las voces que tienen que ver con el mundo de la medicina, entendida ésta en el amplio sentido medieval de la materia ${ }^{11}$.

Con los precedentes mencionados, entramos en el primer gran referente de la lexicografía española que es el Universal Vocabulario (1490) de Alfonso Fdez. de Palencia ${ }^{12}$, que si bien es un diccionario latino cuya finalidad es remediar “...la grand difficultad que incurren los de españa mediana mente principiados enla latinidad: quando por vocablos latinos menos conoscidos buscan de entender los no conoscidos", no se puede olvidar la intención primera y el encargo, en definitiva, que el autor recibe de la reina D. ${ }^{a}$ Isabel, quien le mandó "...tomasse cargo de interpretar los vocablos dela lengua latina segund la declaraçión del vulgar castellano (que se dize Romançe)". Esto es lo que explica la distribución de la obra en dos columnas, izquierda estrictamente en latín y derecha con la traducción castellana, aunque conservando ambas columnas el mismo orden alfabético e idénticas agrupaciones lesemáticas en el interior de cada artículo. Las voces romances que aparecen se justifican por el hecho de ser aclaraciones de las voces latinas que encabezan las entradas o de las familias léxicas del interior.

La obra de Palencia es de extraordinario interés para la historia de la lengua, pero de dificilísima explotación didáctica, puesto que no es posible

\footnotetext{
${ }^{10}$ Breuis grammatica in laudem reuerendissimi episcopi burgensis domini ludouici acunna et rectae et optimae dedicata. En el colofón: 12 de marzo de 1485, Burgos, Fredericus burgis [Federico Biel, o Fadrique de Basilea], Biblioteca Nacional de Madrid, I/264. Otras ediciones en 1491 (I-728) y 1497 (R-2418) con escasísimos añadidos. En el folio 90r comienza un vocabulario "Totius opusculi significationes uocabulorum secundum ordinem alphabeti digestae hae fere sunt", que se prolonga hasta el fol. 104v.

${ }^{11}$ Véase mi trabajo El léxico medicinal en la "Brevis Grammatica» de A. Gutiérrez Cerezo, homenaje a M. ${ }^{\mathbf{a}}$ Teresa Herrera, Madrid, Universidad de Educación a Distancia, 1999.

${ }_{12} \mathrm{Al}$ respecto, puede verse Haebler: Bibliografia Ibérica del siglo $\mathrm{XV}$, La Haya, Leipzig, 1903-1927, n. ${ }^{\circ}$ 510; también A. Paz y Melia: El Cronista Alfonso de Palencia, Madrid, Tip. de la Revista de Archivos, 1914.

El Universal vocabulario en latín y en romance (Paulus de Colonia Alemanus, Sevilla, 1490) fue reproducido, en edición facsimilar, por la Comisión Permanente de la Asociación de Academias de la Lengua Española, Madrid, 2 vols., 1967.
} 
encontrar un criterio uniforme en su confección, hecho que dificulta cualquier acercamiento a ella. Probablemente esta sea la razón de que salvo el elenco de voces internas que realizó John M. Hill ${ }^{13}$, en 1957, no exista otra explotación de esta rica obra. Y es que no sólo la manera de definir, unas veces por equivalentes directos de las voces latinas, (abdicare; es repudiar o aterreçer o desechar por abominable; abiugare, es dividir o apartar), otras mediante explicaciones (abyssus, del género femenino, es fondura de aguas que penetrar no se puede, donde salen fuentes y ríos. Et assí mesmo significa profundidad de escripturas o infierno; auxilia, olla pequeña, ca los antiguos dizían aulas, alas que nos dizimos ollas, por que ninguna letra doblauan, assí que dizían aulicona, lo quese cozía enlas ollas); otras recurriendo a familias léxicas, (abigeus, es ladrón que furta yeguas o pécoras; dize se $a b$ abigendo, o es el que por engaño lieua sieruo aieno ca abigere es apartar o leuar de vn logar a otro y engañar, do se dize abactor), sino también la propia presentación de los materiales, donde podemos encontrar bajo una sola entrada referencia a voces castellanas imprevisibles (por ej., el lat. agon equivale al cast. lid o deseo, pero en la misma entrada encontramos peleador y contienda; agoronomus: príncipe, es el portal que recoge belicoso, victorioso, agonístico, horambrera, lengua, destruyr, consumir, dilapidar, monstruo, todo lo cual dificulta el estudio y explotación de esta obra, con criterios definidos y estables. A pesar de ello y sin negar que $\mathrm{Ne}-$ brija es el punto de referencia indiscutible de la lexicografía española, creo que también es cierto que Palencia es un hito innegable.

Siguen al Universal Vocabulario los dos diccionarios de Nebrija: el Dictionarium latino-hispanicum (Salamanca, 1492) y el Vocabulario de romance en latín (Salamanca, ca. 1495). No voy a entrar tampoco en estos diccionarios que quedan al margen de mi preocupación actual. Solo afirmaré que entre uno y otro hay no pocas diferencias léxicas, como tendré oportunidad de demostrar en breve.

Mayor interés para mi objetivo inmediato tiene un "Latina uocabula ex iure ciuile in uoces hispanienses interpretata" que encontramos entre los fols. eVIr y eVIIIv de la obra nebrisense Iuris ciuilis lexicon o Aenigmata juris civilis $^{14}$, título este último con el que también aparece identificada. Y no es que se trate de dos textos diferentes, sino de un caso típico de emi-

${ }^{13}$ John M. Hill, Universal vocabulario de Alfonso de Palencia. Registro de voces españolas internas, Madrid, R.A.E., 1957.

${ }^{14}$ El Iuris ciuilis lexicon se imprimió en Salamanca, en el taller de Juan de Porras, en 1506. A veces se acompaña de un cuadernillo de seis hojas, titulado Aenigmata juris civilis, que fue impreso en Logroño (1506) por Arnao. Así ocurre en los ejemplares de la B.N. de Madrid, R/7687 y R/14059, el primero sin las seis mencionadas hojas, y el segundo con ellas. Para nuestros fines es indistinto seguir uno $u$ otro. 
sión, como ya puso de relieve Julián Martín Abad ${ }^{15}$. En todo caso, el Latina uocabula no es otra cosa que la recopilación de todas y cada una de las voces que se estudian en el texto básico del Iuris ciuilis.

Al margen de las cuestiones tipobibliográficas, importa dejar constancia de que en las páginas señaladas existe un total de 664 voces castellanas, como equivalentes de otras tantas latinas presentadas con ordenación alfabética y que van de $a b a x$ (primera voz) a zona (última). Este vocabulario no debe confundirse con el denominado por Carlos Humberto Núñez ${ }^{16}$ Parvum vocabularium (Novae iuris civilis dictiones, según José Perona ${ }^{17}$ ), que aparece (al menos en algunos ejemplares; en el de la B.N. de Madrid, R/14059, ocupa las páginas A-aVIII) tras nuestro "Latina vocabula" y que no es un verdadero vocabulario, puesto que se reduce a ciertos comentarios jurídicos en los que en muy pocas ocasiones encontramos un equivalente romance. Tampoco debe confundirse con el Paruum vocabularium que aparece en algunas ediciones de las Introductiones, según dejé constancia antes, y que es el epígrafe general bajo el que Nebrija recoge un vocabulario temático.

Al propio Nebrija se debe también el Lexicon artis medicamentaria, esto es, el listado de cerca de 2.000 nombres de términos griegos y latinos, relativos al mundo de la medicina (entendida ésta en el amplio sentido medieval del término), muchos de los cuales tienen su correspondiente caste1lano. Nebrija publica este glosario en la edición a su cargo del De medicinali materia de Dioscórides, Alcalá $1518^{18}$, y es precisamente con ocasión de esta edición cuando encontramos la segunda alusión a la elaboración del Dictionarium medicum. Recordemos que la primera fue en 1506 cuando en el Prefacio de los Aenigmata afirmaba: Itaque post iuris ciuilis vocabularium dabimus id quod ad medicinam confert, a continuación de lo cual se refería al tercero de los repertorios que, de acuerdo con su esquema inicial, cerraba la gran obra de los vocablos: la Teología (deinde quod ad utriusque instrumenti multarum rerum earumque difficallimarum cognitionem maxime est conducibile...).

\footnotetext{
${ }^{15}$ Véase "Nebrija en los talleres de Arnao Guillén de Brocar y Miguel de Eguía", pág. 30.

${ }^{16}$ Elio Antonio de Nebrija, Léxico de derecho civil (texto latino y castellano. Notas y prólogo de C. H. Núñez), Madrid, C.S.I.C., 1944.

${ }_{17}$ Véase la primera conclusión de su trabajo: "Aelii Antonii Nebrissensis novae iuris civilis dictiones per ordinem alphabetarum digestae", en Homenaje al Profesor Luis Rubio, Murcia, Universidad de Murcia, 1987-89, vol. II, pág. 1113.

${ }^{18} \mathrm{La}$ obra de Dioscórides recoge los caracteres, efectos y empleo de aproximadamente 600 plantas, lo que supone el saber farmacológico del primer siglo de nuestra Era. Durante toda la Edad Media se multiplicaron los manuscritos griegos de este texto y se tradujo al latín y al árabe. En 1516 apareció en París una de las ediciones latinas más apreciadas, la de Ruellio, que es de la que parte Nebrija para publicar, en Alcalá (1518), la primera edición latina del Dioscórides, a la cual se añade el índice mencionado.
} 
La edición de Dioscórides obligó a Nebrija a encararse con la materia médica, lo que le permitió valorar mejor el trabajo ya anunciado en 1506. Así, en la Salutación al lector de la edición alcalaína del Dioscórides leemos: Cum in eo essem temporis articulo, iucundissime lector, quo traditurus eram impressoribus lexicon illarum uocum que ad medicamentariam artem pertineret, subito simulque apparuerunt gemine Dioscoridis interpretationes Hermolai Barbari altera, atque altera Ioannis Ruelli Suessionensis. "Itaque continui me ne precipitarem editionem antea quam iis de rebus que sunt huius negotii proprie, inter se conferrem doctissimorun interpretum ingenia eodem opere».

Pero este glosario de la edición alcalaína del Dioscórides, donde encontramos numerosas voces hispánicas (Adiecimus praeterea in quibusdam uoces hispanas illis uidelicet de quibus apud omnes fere constabat significatio), no es el "Vocabulario de Medicina encuadernado en pergamino que se contenía en cierta arca de la Universidad de Alcalá, que resguardaba diversas apuntaciones y manuscritos dejados en depósito por el mismo Nebrija y que su hijo Sebastián recogió en 1523, obligándose a estamparlos en las prensas complutenses si se ovieren de imprimir", a que se refiere Armando Cotarelo en su Nebrija Científico ${ }^{19}$. El diccionario médico a que alude Nebrija en las dos ocasiones mencionadas es el que apareció entremezclado en la edición del Dictionarium latino-hispanicum que el editor Jean Steelsius $^{20}$ publicó en Amberes en 1545. Las aprox. 2.500 voces que integraban el aludido diccionario se insertaron en esta edición, precedidas de una cruz, a lo largo de toda la ordenación alfabética. De nuevo se reprodujeron en 1553. A partir de 1560 el médico y humanista judío-portugués Luís Nunes, a quien Steelsius encarga de la edición, hace desaparecer todos los arabismos incluidos hasta la letra 'o', que no habían podido suprimirse en las ediciones de 1545 y 1553, añade algunos términos nuevos y corrige errores gráficos, con lo que queda definida la edición que se mantendrá en el futuro. En España, el léxico médico aparece en la edición barcelonesa que del Dictionarium nebrisense hace Antic Roca, en 1560.

En 1520 se documenta un Vocabulaire pour apprendre Franchoys, Espagnol y Flaming, impreso en Amberes por W. Vorsterman. La rareza de

${ }^{19}$ Edic. cit., pág. 14.

20 Véase J. Peeters-Fontainas, Bibliographie des impressions espagnoles des Pays-Bas méridionaux, 2 vols., Nieuwkoop/Pays-Bas, B. De Graaf, 1965, noticia 825.

Datos más minuciosos sobre la incorporación y permanencia del léxico médico recogido en la edición de Steelsio, así como valoración de los criterios de selección del propio vocabulario, pueden encontrarse en Enrique Montero y Avelina Carrera de la Red, «El dictionarivm medicvm de E.A. de Nebrija», en Antonio de Nebrija: Edad Media y Renacimiento, Salamanca, Ediciones Universidad de Salamanca, 1994, págs. 399-411. 
esta obra ${ }^{21}$ y el desconocimiento de la misma por los pocos que la citan ha hecho, entiendo, que se clasifique mal su contenido. Efectivamente es la primera obra de enseñanza de español a extranjeros de que existe documentación, pero en mi opinión no puede ser tenida en cuenta en una historia de la lexicografía española puesto que no hay en ella repertorios léxicos. Las correspondencias que se establecen entre las tres lenguas citadas en el título y presentadas por columnas, según el orden indicado en el propio título, son fundamentalmente fraseológicas, sin orden alfabético alguno, inscritas en los contextos temáticos en que se mueve la línea de los libros de diálogos, de tan antigua tradición y tan difundidos en los siglos XVI y XVII. El Vocabulario en cuestión, reproducido de nuevo en $1530^{22}$, tiene algunas correspondencias de términos, pero aisladas y sin finalidad lexicográfica, como ocurre muchas veces con las gramáticas castellanas para extranjeros, publicadas a lo largo del Siglo de Oro. En este caso se trata de un método sencillo y rápido de aprendizaje de lenguas, en base a abordar situaciones elementales.

Hay, sin embargo, una obra de esta época, de clara finalidad didáctica también, que sí debe ser relacionada en la nómina de los repertorios lexicográficos de los que me ocupo, a pesar de la complejidad que su explotación lexicográfica ofrece, no sólo porque el español está lleno de errores, lo que nos lleva a pensar que quien lo hizo y/o corrigió no conocía la lengua, sino también porque junto a formas primitivas aparecen derivados e idénticas voces con diferentes preposiciones, etc. En el prólogo, en cinco lenguas, que hay al comienzo leemos: "Utilíssimo vocabulario para los que dessean, sin yr a la escuela (como son offiçiales e mugeres) apprender latín, italiano, franços, espagnuol e alemán, porque en él se contienen todos los nombres, vocablos e palabras que se pueden proferir en diuersos modos". Me refiero al Quinque linguarum... ${ }^{23}$, editado en Venecia, 1526, por Francisco Garonus, y reeditado más tarde, $1533^{24}$, en el mismo lugar y por el mismo editor.

En el prólogo mencionado, a continuación del texto transcrito, se dice: "Este libro se llama vna entrodución o puerta para los que quieren apren-

${ }^{21}$ J. Peeters-Fontainas, noticia 297 de la edición citada, describe el ejemplar del que nos consta su existencia en la Biblioteca del Congreso, PC-2689,V56, que es el que manejo.

${ }_{22}$ Bajo el título Vocabulaire en troys langues, cest assauoir, francoys, flameng et espagnol, también en Amberes, por el mismo editor.

${ }_{23}$ Quinque linguarum vtilissimus uocabulista Latine. Tusche. Galliche. Hyspane. \& Alemanice. Ualde necessarius per mundum versari cupientibus. Nouiter per Franciscum Garonum maxima diligentia in lucem elaboratus (título parcialmente repetido en las lenguas del texto), Franciscum Garonum, Venecia, 1526. Manejo el ejemplar de la Bibliteca Nazionale Marciana de Venecia, misc. 1528.7

${ }^{24}$ Palau (VII, pág. 219) registra una edición en cinco lenguas (Venecia, 1513) que creo es un error por 1531 (Nuremberg). 
der las lenguas...", lo que curiosamente es el mismo título del antecedente de esta obra al cual se refiere Annamaría Gallina ${ }^{25}$.

El texto de Garonus es bastante pobre por el número de páginas, 69 en total, aunque no así por el léxico contenido en las mismas (más de 2.300 entradas) que aborda el relativo a las partes del cuerpo, los sentidos, etc., y se estructura en sesenta y cuatro capítulos (cincuenta y cinco correspondientes al libro primero y nueve al segundo), los mismos que tiene el Introito (su antecedente) y con la misma enumeración, aunque con distinto orden, lo que me lleva a pensar que estamos ante una nueva versión. Hasta donde conozco, se trata del primer vocabulario temático en que aparece el español, bastante anterior a los vocabularios alfabéticos que enlazan con la línea de Noël de Berlaimont ${ }^{26}$ en los que volvemos a encontrar el español. La familia de estos vocabularios plurilingües, distinta -insisto- de la de los que siguen a Berlaimont es también muy amplia, puesto que llega hasta los de ocho' lenguas (el primero de estos en 1546). Consta también la presencia del español en los de seis, siete y ocho lenguas.

Aunque Gili Gaya, en su Tesoro, documenta en 1565 el repertorio léxico que Alejo Venegas ${ }^{27}$ recoge en la Agonía del tránsito de la muerte, hay que retrotraerlo hasta 1543 , fecha de la tercera edición de esta obra, donde se incluye, con portada propia, una segunda parte, titulada Breue declaración de las sentencias y vocablos obscuros que enel libro del tránsito de la muerte se hallan, escripta porel mismo autor Alexio Venegas. Sin embargo, hasta el capítulo VIII, de la segunda parte, "De vna particular declaración de

${ }^{25}$ Véase su Contributi alla storia delle lessicografia italo-spagnola dei secoli XVI e XVII, Florencia, Leo O. Olschki Ed., 1959. El antecedente en cuestión es el impreso en Venecia, 1477 , por Adamo de Roduilla, titulado Questo libro el quale si chiama introito e porta..., que es una nomenclatura bilingüe (italiano-alemán) de la que se ocupa la propia Annamaría Gallina (págs. 27 y sgtes.). Siguen a esta edición otras, entre ellas una en cuatro lenguas (Roma, 1510) y la de cinco, que cito, por recoger el español.

Son pocos los datos que conocemos del impresor italiano: trabajó en Bolonia (1524), Venecia (1524-1527), Chivasso (1529-1533) y Asti (1535-1541). Tal vez, cuando aparezca el tomo correspondiente del Dizzionario dei tipografi e degli editori italiani: Il Cinquecento, Diretto da Marco Menato, Ennio Sandal, Giuseppina Zapella, Milano, Editrice bibliografica, 1997, podamos saber más sobre este impresor.

26 Este maestro de lenguas publicó en Amberes (W. Vosterman, 1530) un vocabulario para aprender flamenco y francés. Aunque no se conservan ejemplares de esa edición, parece que su estructura debió ser igual a otra de 1536, dividida en dos partes, que contiene tres diálogos, algunos modelos de cartas, un glosario, unas reglas de pronunciación del francés y algunas plegarias. El título, pues, representa parcialmente el contenido. El hecho es que esta obra, sucesivamente ampliada y modificada en cuanto a las reglas incluidas, llegó a convertirse en toda Europa en un libro básico de bolsillo para aprender lenguas, a lo largo de los siglos XVI y XVII.

${ }^{27}$ Alexio Uenegas [sic], Agonía del tránsito de la muerte, con los avisos y consuelos que acerca della son prouechosos, Juan de Ayala, Toledo, 1543. 
algunos vocablos: que enel presente libro del tránsito: por diuersos capítulos están esparzidos", no comienza realmente el listado de las 275 voces que tengo identificadas.

Precisamente, antes de detenerme en el primero de esos vocabularios plurilingües que arrancan del de Berlaimont, en el que aparece por primera vez el español, Vocabulario en cuatro lenguas (Lovaina, 1551), quisiera referirme, bien que de pasada, a tres obras que en un estudio lexicográfico deben ser tenidas en cuenta, aunque sea para desechar alguna de ellas. Son estas: el Diálogo de la lengua de Juan de Valdés ${ }^{28}$, 1535, Las Leyes de todos de los reynos de Castilla $^{29}$ de Hugo de Celso, 1538, y el Quatri Partitu de Alonso de Chaves, también de 1538.

El primero, ya se sabe que no es una obra de carácter lexicográfico, especialmente por su forma; sin embargo, la gran cantidad de información que para una historia del léxico español aporta, hace que deba ser tenida en cuenta en una elaboración como la nuestra.

Las Leyes de todos los reynos de Castilla es una obra bastante extensa que por su disposición formal (ordenación alfabética de diferentes términos: abad, abbadesa, abejas, abigeo, abito, abogado...) pudiera llevarnos a pensar en un repertorio lexicográfico más. Sin embargo, cuando se analiza más en profundidad, se comprende que el lema de entrada es una excusa para dar a conocer la legislación que sobre el término en cuestión existe, así como información de carácter enciclopédico. Es cierto que en ocasiones existen verdaderas definiciones de carácter lexicográfico y que por ello solo, junto al aspecto formal antes mencionado, sería suficiente para que sea tenida en cuenta en nuestro trabajo. Los artículos presentan una extensión muy desigual y mucha de la información que contienen no interesa para los fines lexicográficos; a pesar de ello, es posible encontrar, generalmente en los comienzos del artículo, definiciones, explicaciones o equivalencias que hay que tener en cuenta. Así, en abbad leemos: "es el perlado mayor del monesterio de qualquier orden que sea...", a lo que sigue otra información con características, deberes del mismo, relación con su obispo, etc., todo ello encaminado a conocer la normativa que sobre tal cargo existía en el Reyno de Castilla. Lo mismo ocurre con otras palabras, en unos casos de manera más prolija que en otros; abadessa: "en monesterio de monjas, es perlado mayor, como el abbad lo es en monesterio de religiosos...”; citación: "qué es y cómo deue hazer, véase en yu-

\footnotetext{
${ }^{28}$ Sigo la edición de Juan M. Lope Blanch, Madrid, Castalia, 1969.

${ }^{29}$ Hugo de Celso, Las leyes de todos los reynos de Castilla: abreuiadas y reduzidas en forma de Repertorio decisiuo por la orden del A.B.C., Valladolid, Nicolás Tyerri, 1538. Utilizo el ejemplar de la B.N. de Madrid, R/15403.
} 
so capítulo emplazamiento". A pesar del discutible carácter lexicográfico, entiendo que estamos ante un repertorio que no debe desconocerse en un inventario de la lexicografía española, puesto que son 984 voces las registradas en él.

Alonso de Chaves $^{30}$ escribe, entre 1520 y 1538, según Cesáreo Fdez. Duro, su Quatri partitu Encosmographia Pratica I por otro nombre llamado Espeio de navegantes, primera de las recopilaciones de terminología náutica conocidas, que se conserva en la Academia de la Historia, de Madrid $^{31}$. La datación de este ms. puede hacerse a partir del texto en que su autor explica la tabla del número Áureo: "Por manera que el año 1520 fue uno de Áureo número, e acabados los dichos diez e nueve años, que será a fin del año 1538 , tornará otra vez a comenzar"32. Las formas verbales fue y será marcan los términos de datación del manuscrito. El Quatripartitu, único texto suyo conocido, consta de tres libros o partes, cada uno de ellos dividido en tratados y éstos, a su vez, en capítulos. Los dos primeros libros en los que se abordan cuestiones de reglas, tablas y ejemplos que debían tenerse en cuenta para la confección del almanaque, así como múltiples aspectos de ciencia meteorológica, carecen de interés para nosotros, aunque probablemente sea lo más significativo de la obra. Es el primero de los seis - capítulos que integran el tratado tercero y último, "que tracta de la Nao e de sus partes y de los vocablos usitados en la navegación", el único que nos interesa desde el punto de vista lexicográfico.

Comienza Chaves definiendo las clases de navíos: "Declararé — dice— los nombres de todos los géneros de navíos de vela y remos que en común se usan en España, comenzando del menor hasta el mayor conforme a la orden que sigue”. Y figuran a continuación los nombres de copanetes, esquifes, chalupas, galeones, etc., para pasar más tarde a definir el aparejo de las embarcaciones con una precisión asombrosa, como demuestra el primero de los lemas: "acolladores, se llaman aquellos cabos delgados con que se atesan los obenques a las bigotas y cadenas". Y así hasta un total de 152 voces.

\footnotetext{
${ }^{30}$ Fue Alonso de Chaves (sevillano nacido a finales del siglo xv) piloto mayor y cosmógrafo de Carlos V, según consta en la portada del propio manuscrito. Las pocas y a veces contradictorias noticias que sobre él tenemos nos dicen que fue hombre ligado al mar y a la enseñanza, ocupando en distintas ocasiones la cátedra de cosmografía que desde 1552 sería propiedad de su hijo Jerónimo de Chaves, autor de una Chronologia o repertorio que gozó de varias ediciones en su tiempo.

${ }^{31}$ Ms. $9 / 2791$ (folios $56 \mathrm{v}$ a $62 \mathrm{v}$ para el vocabulario). Fue publicado parcialmente por Cesáreo Fernández Duro en la Revista de Navegación y Comercio, años VI y VII (1894/95), números 144 a 152 , bajo el título "De algunas obras desconocidas de cosmografía y de navegación y singularmente de la que escribió Alonso de Chaves a principios del siglo XVI".

32 C. Fernández Duro, ob. cit., núm. 144, pág. 477.
} 
$\mathrm{Y}$ vuelvo en este punto a referirme al Vocabulario de quatro lenguas, tudesco, francés, latino y español, muy prouechoso para los que quisieren aprender estas lenguas, impreso por Bartolomé Gravio, en Lovaina, $1551^{33}$. Como ya dije, es el primero de los repertorios plurilingües que enlazan con la línea abierta por Noël de Berlaimont en los que vemos la presencia del español ${ }^{34}$. Después seguirían otras varias ediciones en las que nuestra lengua continuaría apareciendo, con combinaciones diversas, hasta $c$. 1585 en que se edita el Vocabulario en ocho lenguas, última de las recopilaciones de este tipo, aunque ello no quiere decir que la fecha suponga también la desaparición de esta clase de obras, puesto que la edición de ocho lenguas vuelve a publicarse en Bolonia en 1692.

El Anónimo de 1551 está dividido en dos partes: la primera, integrada por cuatro capítulos, son coloquios con la estructura habitual en este tipo de textos; la segunda es un repertorio léxico, según se dice en la introducción, ordenado alfabéticamente, aunque a la vista del propio texto se comprueba que tal orden no es cierto, sino que responde a un extraño criterio de categorías gramaticales, no siempre respetado. El orden de presentación de voces se encuentra encabezado por el flamenco, seguido del francés, latín y, finalmente, el español. Al final de la segunda parte hay unas reglas para leer y hablar perfectamente francés, escritas en flamenco y en latín; siguen unas oraciones en las cuatro lenguas, con lo que se acaba la obra ${ }^{35}$.

El léxico aquí recogido se aproxima a las 1.500 voces. Contrastadas con las que aparecen en el Garonus, aunque mi valoración es muy provisional,

\footnotetext{
${ }^{33}$ Véase la descripción en Peeters-Fontainas, noticia 303.

${ }^{34}$ Los vocabularios plurilingües con inclusión del español que se publicaron en esta época en los Países Bajos son muy numerosos. Al propio Bartolomé Gravio se deben varios de ellos, aunque el título no siempre sea coincidente. Otro tanto cabe decir del impresor Jean Verwithaghen. Peeters-Fontainas registra hasta diecisiete en cuatro lenguas, dentro del siglo XVI. Y, al menos hasta 1647, se mantienen ediciones en cuatro lenguas. En cinco lenguas (latín, alemán, francés, español e italiano) tenemos una edición de J. Steelsius en 1534 y en seis lenguas son numerosas las documentadas a partir de la de Henry Hendrickx, de 1576. De siete lenguas tenemos también, a partir de la Jean Critinus, 1540, varias ediciones en las que junto a los colloquia aparece el consabido diccionario. Menos numerosas, por lo que respecta a los Países Bajos, son las dedicadas a ocho lenguas, posibles de rastrear hasta $c .1585$. Todo ello, insisto, por lo que respeta a una lengua (español) y a un ámbito geográfico (Países Bajos). Pero las impresiones se produjeron también en otros países y con lenguas diferentes, lo que demuestra la gran popularidad que alcanzó este tipo de libros o método de adquisición rápida de una lengua extranjera.

${ }_{35}$ Parto del único ejemplar conocido, conservado en la Bibliothèque Mazarine de París, falto de los folios $\mathrm{I}^{3}$ a $\mathrm{M}^{4}$, que no afectan a nuestro objetivo.

Hay otras varias ediciones de vocabularios en cuatro lenguas (véase Peeters-Fontainas, noticias 304 a 327) donde se van sustituyendo unas por otras, fenómeno que se repite hasta el Dictionaire en huit langues (Amberes, c. 1585) que es el más amplio de este tipo de repertorios.
} 
entiendo que nada tienen que ver, y que se trata de dos líneas diferentes de vocabularios políglotas.

En 1553, Gabriel Giolito publica en Venecia una edición de la Tragicomecia di Calisto e Melibea o Celestina con una introducción de Alfonso de Ulloa $^{36}$ "nella quale s'insegna pronuntiare la lingua Spagnola", añadiendo al final de la obra una exposición de los vocablos difíciles contenidos en dicha obra. La nómina de estas voces llega casi hasta las 900 .

El mismo editor, en el mismo lugar y año, publica también una edición española del Orlando Furioso, traducida por Jerónimo de Urrea, a la que Ulloa añade al final una Introducción..., con una exposición en la Thoscana de todos los vocablos difficultosos contenidos en el presente libro. Ya dije en 1991, a propósito de estas ediciones y frente a las tesis mantenidas por Amado Alonso, que, en primer lugar, la edición del Orlando Furioso es anterior a la de la Celestina y que por lo mismo no pudo copiarla; y, en segundo lugar, que el léxico de una y otra presenta muy pocas coincidencias y que, en aquellos casos en los que se coincide, la manera de encarar la explicación es diferente. La coincidencia, la veía yo, en la utilización del vocabulario de Nebrija para fijar significados y establecer la equivalencia latina de no pocas voces. El antecedente creo que es importante por cuanto se adelanta 17 años al primer diccionario español-italiano de Cristóbal de las Casas, primero, por otra parte, de los diccionarios españolotra lengua.

Precisamente un año más tarde, en 1554, tenemos el primer testimonio o, mejor, los dos primeros testimonios de repertorios hispano-ingleses, ambos anónimos, probablemente publicados con motivo del matrimonio en segundas nupcias de Felipe II con María Tudor, hija de Enrique VIII. El primero (el orden no indica prelación temporal), $A$ very profitable booke ${ }^{37}$, es un breve manual para la enseñanza del español a ingleses, dividido en dos partes. La primera de ellas consta de cuatro capítulos, de los cuales tres son diálogos y el cuarto unas reglas para escribir cartas. En la segunda parte, que ocupa los fols. D.villv al H.vir, aparece el vocabulario, al que siguen dos hojas más con oraciones. Las palabras se presentan a doble columna, a

\footnotetext{
${ }^{36}$ Un estudio comparativo sobre el léxico recogido por Alfonso de Ulloa en ambas ediciones puede verse en mi trabajo "Los glosarios de 1553 de A. de Ulloa», en RFE, LXXI, 1991, págs. 253-285.

37 A very profitable booke to lerne the maner of redyng writyng \& speakyng english \& Spanish. Libro muy prouechoso para saber la manera de leer, y screuir, y hablar Angleis, y Espa$\tilde{n} o l$, Londres, 1554, al final: John Kyngston y Henry Sutton para John Wyght. El libro es muy raro y tan sólo se conserva en un ejemplar de la British Library (C. 175. bb. 11[2]), del cual se publicó una edición facsimilar (The Scolar Press, Menston, 1971), que es la que utilizo.
} 
la izquierda el inglés y a la derecha el español, sin un orden aparente, pese a que en el índice y en las palabras que encabezan el elenco se nos informa de que siguen el del abc, aunque se agrupan las voces por categorías gramaticales. La fuente es una de las versiones políglotas del vocabulario de Noël de Berlaimont en el que las palabras se alfabetizaban por el flamenco; al desaparecer esta lengua se pierde la guía del orden. En el texto del repertorio hay algunas erratas, desajustes en las equivalencias, además de aparecer un mismo artículo repetido en su integridad.

El otro texto, The boke of Englysche and Spanysche $e^{38}$, es un pequeño repertorio temático de apenas 28 páginas en el que las voces se presentan en dos columnas, aunque no contrapuestas. La forma inglesa precede a la española. La manera de exponer los materiales en los primeros capítulos más se parece a uno de tantos diálogos gramaticales que circulaban por Europa que a un vocabulario, ya que son raras las equivalencias palabra a palabra, correspondencia que suele ser más frecuente en otros textos. En esos primeros capítulos las voces figuran construidas con otros elementos, por lo que algunas de ellas se repiten, especialmente los verbos cuando se muestran diversas formas del paradigma en otras tantas construcciones. Son muy abundantes las erratas, a pesar del reducido número de voces incluidas (en torno a 600). Sin embargo, por lo temprano de la aparición de ambos, considero que es importante tenerlos en cuenta y especialmente porque casi nadie se ha fijado en ellos.

En 1555 volvemos a encontrarnos con una nueva edición del Dioscórides $^{39}$. Pero esta vez es una edición en castellano (la primera), con abundantes anotaciones y referencias a plantas hispanas, que tienen un gran interés para la datación del léxico especializado. La edición es importante por cuanto que su autor, el Doctor Andrés Laguna, segoviano, de origen judío, fue un gran humanista que recorrió la Europa de su tiempo, estudió con Ruellio en París, y pudo investigar en los más diversos campos, según nos da a conocer Teófilo Fernando Ortega en la Introducción y Comentarios a la edición moderna de esta obra, que hizo en 1968 el Instituto de España.

Pues bien, al final del texto de 1555 , concretamente en las págs. 618 y 619 hay una Declaración siguiendo el orden del A. B. C. de algunos vocablos obscuros y no muy recebidos en nuestra lengua vulgar. La lista no es muy amplia, aunque completada con la Tabla de los nombres castellanos,

\footnotetext{
${ }^{38}$ The boke of Englysche and Spanysche $e^{38}$, Londres, Robert Wyer, 1554. De la obra tan sólo se conserva un ejemplar, en la British Library (C. 175. bb. 11[1]), del que en 1971, poco después de su adquisición, hizo una reproducción facsimilar The Scolar Press, en Menston, que es la versión que utilizo.

${ }_{39}$ Dioscórides, De medicinali materia .... Ioanne Ruellio Suessionensi interprete. [Ed. lit. Antonio de Nebrija], Compluti Carpetaniae, in officina Arnaldi Guillelmi [Brocarii], 1518.
} 
entre los quales van algunos estrangeros, pero españolizados, donde aparecen documentadas muchas más voces específicas, resulta de gran interés.

El manuscrito 8431 de la B.N. de Madrid ${ }^{40}$ sigue al día de hoy parcialmente inédito, después de que en 1958 Manuel Agud y Luis Michelena ${ }^{41}$ editaran la parte correspondiente a la lengua cántabra. Lo menciono por su carácter de manuscrito y el abandono sufrido, y creo que, dada la fecha, 1562 , debe ser tenido en cuenta.

De 1564 es el manuscrito llegado a nosotros por copia de Martín Fernández Navarrete, hecha y confrontada el 6 de octubre de 1791 con el original existente en la Biblioteca de El Escorial ${ }^{42}$, según indica el propio Fernández Navarrete al final de su manuscrito. También aventura este autor, a la luz de la existencia de un cuaderno de Geografía que precede al Arte de marear en el original de El Escorial (sacado de varios autores en 1557), que el autor Juan de Moya que aparece al comienzo del manuscrito pudiera ser el canónigo granadino Juan Pérez de Moya, que en 1563 imprime unos Fragmentos matemáticos con cuestiones relativas a geografía, astrolabios y navegación.

El Arte de marear de Juan de $\mathrm{Moya}^{43}$ es una obra que trata diversas cuestiones sobre el arte de navegar propiamente dicho, entre las que destacan las relativas a los vientos, mareas y otros aspectos que inciden en la orientación de los barcos. Al comienzo de la misma, concretamente en los párrafos segundo y tercero, nos encontramos con las primeras definiciones de carácter lexicográfico: "rumbo son las rayas de las cartas de marear que

\footnotetext{
${ }^{40}$ Nicolás Landuchio, Dictionarium Linguae Toscanae, Anno IDLXII. A Nicholao Landuchio, ciuitatis Lucae regionis Toscaniae, suae vernaculae linguae peritissimo. Bocabulario Español, Italiano, Francés y Vizcayno [esto último, añadido]. Manuscrito de la Biblioteca Nacional, año 1562 (sign. Ms. 8.431), 328 folios. El diccionario español-italiano llega hasta el fol. 107. Al fol. 114r.: Dictionarium Linguae Franconiae, Año 1562. A Nicholao Landuchio ciuitatis Lucae Regionis Toscaniae vernaculae suae Linguae atque Franconiae Peritissimo. Sigue el diccionario español-francés hasta el fol. 220. Al fol. 226r.: Dictionarium Linguae Cantabricae, Anno milessimo Quingentessimo sexagessimo secundo. Soli Deo honor et Gloria. Al fol. 226v.: Bocabularioa Ezqueras Jaquiteco ezqueras Verba eguiteco... Sigue el diccionario vizcaíno-español hasta el fol. 328. Varias hojas en blanco y con apuntes sin interés.

${ }^{41}$ N. Landuchio Dictionarium Linguae Cantabricae (1562), San Sebastián, imprenta de la diputación de Guipúzcoa, 1958.

${ }^{42}$ El P. Julián Zarco Cuevas, efectivamente, registra en su Catálogo de los manuscritos castellanos de la biblioteca de El Escorial, Madrid, Imprenta Helénica, 3 vols. 1924-1929, concretamente en el tomo II, pág. 263, el mencionado ms. Por lo que se refiere a la copia de Fernández Navarrete se encuentra en el Museo Naval de Madrid, C. D. 9840 75/31.

${ }^{43}$ Utilizo el texto que se encuentra en la Colección de documentos y manuscritos compilados por Fernández Navarrete, vol. 1, prólogo de Julio F. Guillén Tato, Nendeln, Leichtenstein, Kraus-Thomson Organiz. Ltd., 1971, págs. 81-140 (el ejemplar del Ministerio Naval tiene la signatura $\mathrm{MN}-8$, Doc. 4).
} 
se ponen por los vientos; derrota dizen los marineros por decir de do y a do va, quiero decir que es el camino que por la mar se hace o deve hazer". Aunque pueden rastrearse otras voces que con justicia pueden figurar en un repertorio lexicográfico, es más adelante, concretamente en el pág. 90 de la edición que manejo, cuando, bajo el epígrafe general de Nombres y vocablos de mareantes que sirven por principios para esta ciencia, encontramos un listado de 86 voces, que son el repertorio a que siempre se hace referencia.

Es evidente que en la época era mucho mas importante lo que pudiéramos llamar teoría naval, es decir, mapas de navegación, derroteros y todo aquello que tuviera que ver con la orientación, que el léxico como tal de las embarcaciones (casco, armamento y aparejo), cosa estable y que no presentaba especiales novedades para las personas familiarizadas con el mar. Esto no impedía que se recogiesen en un tratado didáctico, si bien con importancia matizada. Comparado con el repertorio de Chaves, anteriormente mencionado, el de Moya resulta limitado y caprichoso, ya que no existe en él ninguna sistematicidad o coherencia interna, cosa que sí es posible apreciar en el Quatri Partitu. Por otra parte, es posible asegurar, tras la comparación minuciosa de ambos, que no existe entre ellos conexión alguna ni por el léxico introducido ni por la manera de explicarlo.

En 1565 se publicó en Alcalá, junto con la Grammática con reglas muy provechosa y necessarias para aprender a leer y escriuir la lengua Francesa conferida con la Castellana de Baltasar de Sotomayor, un Vocabvlario de los vocablos que más comunmente se suelen vsar, cuyo autor era Iaques Ledel o Iaques de Liaño, como más habitualmente se suele denominar. La obra de Liaño es un breve léxico francés-español que se limita a dar la traducción de un corto número de voces francesas. El autor lo escribió para la enseñanza elemental del francés entre españoles. Teniendo en cuenta su fecha, casi cuarenta años anterior a los primeros diccionarios hispano-franceses, no deja de ser importante esta obra para la historiografia lexicográfica de la lengua española.

Otros repertorio que no quisiera dejar de mencionar, a pesar de la brevedad de algunos y del carácer disperso y heterogéneo de otros, son los de Argote de Molina, Lorenzo Palmireno, Sánchez de las Brozas, Herrera, López de Velasco y López Tamarid.

El de Argote de Molina lo encontramos al final de la edición de El Conde Lucanor $^{44}$, bajo el epígrafe "Indice de algunos vocablos antiguos que se hallan en este libro, para noticia de la lengua Castellana», al cual precede un

${ }^{44}$ El Conde Lucanor, Compuesto por el excelentíssimo príncipe don Iuán Manuel, hijo del infante don Manuel y nieto del sancto rey don Fernando. Dirigido por Gonçalo de Argote y de Molina, al muy Illustre señor Don Pedro Manvel, Gentil hombre de la Cámara de su Magestad y de su Consejo. Impresso en Seuilla por Hernando Díaz, año 1575. 
breve "Discvrso de la lengva antigua Castellana" que dice textualmente: "Los que vuieren leýdo libros Castellanos de dozientos o trezientos años de antigüedad, verán que en muy pocos dellos se halla tan pura y tan limpia lengua, según aquellos tiempos, como la deste libro que sin duda fue la mejor que entonces se vsó, y aunque en él aya muchos vocablos que parescerán aora estraños y nueuos, pero muy pocos dellos se pueden tener por çafios ni obscuros, como son los que de ordinario se encontrarán en los dichos libros, antes juzgara el que éste leyere ser esta la verdadera y propria lengua Castellana que se hablaua y escreuía aun en tiempo de nuestros abuelos, para noticia de lo qual hize el índice siguiente por orden del A.B.C.”. Son en total 236 voces que conviene tener en cuenta precisamente por esa etiqueta de anticuadas. En la edición de este texto llevada a cabo en Madrid, 1642, se suprimieron del índice de arcaísmos 32 palabras, no sabemos si por descuido o por considerarlas fáciles de entender sin necesidad de aclaración.

Repertorios menores, por su brevedad, aunque no por ello exentos de interés, son los que se encuentran en el Vocabulario del humanista ${ }^{45}$ compuesto por Lorenço Palmyreno: "donde se trata de aues, peces, quadrúpedos, con sus vocablos de caçar y pescar, yeruas, metales, monedas piedras preciosas, gomas, drogas, olores, y otras cosas que el estudioso en letras humanas ha menester". Según se indica en el título, "hay tambien vn vocabulario de antiguallas para entender a Ciceron y Virgilio". Aunque la mayor parte del libro está dedicada a explicar vocablos latinos para la mejor inteligencia de la antigüedad clásica, contiene también unos cuantos vocabularios castellanos, muy breves, que son a los que me refiero.

Con anterioridad al Vocabulario del humanista Palmireno había escrito un De vera et facili imitatione Ciceronis... (Pedro Bernuz, Zaragoza, 1560) donde recoge (entre los folios $\mathrm{L}_{2}$ y $\mathrm{O}_{1}$ ) su Lesicon pverile, agrupado temáticamente y con ordenación alfabética en algunos casos, que es, sin duda, el punto de partida de la más amplia recopilación registrada en el Vocabulario del humanista.

Al profesor salmantino Francisco Sánchez de las Brozas se atribuyen unas Etimologías españolas, adicionadas por Venegas, cuyo manuscrito, según parece procedente de otro más antiguo localizado en El Escorial ${ }^{46}$, se guarda en la R.A.E. Son algo más de 1.200 palabras, ordenadas alfabéticamente, que a pesar del poco valor actual que en el terreno científico ofre-

\footnotetext{
45 Juan Lorezo Palmireno, Vocabulario del humanista [...] donde se trata aues, peces, quadripedos, con sus vocablos de caçar, y pescar, yeruas, metales, monedas, piedras preciosas, gomas, drogas, olores, y otras cosas que el estudioso en letras humanas ha menester, Pedro de Huete, Valencia, 1569 (B.N. R/159589). De esta edición se ha hecho un facsímil, con prólogo de Andrés Gallego Barnés, en Valencia, F. Domenech, 1978.

${ }^{46}$ Véase descripción en La Viñaza, núm. 788.
} 
cen las etimologías allí dadas, no deja de tener interés el listado por la fecha de su documentación.

En los Comentarios de Fernando de Herrera ${ }^{47}$ a la obra de Garcilaso, se encuentra abundante información lexicográfica. Es cierto que la propia estructura e incluso naturaleza del texto dificulta la recopilación. Pero me parece también que la definición y explicación de las 104 voces que he podido constatar como rescatables para nuestros fines, justifican que sea tenido en cuenta este texto.

La Orthographía castellana ${ }^{48}$ de uno de nuestro más interesantes teóricos de la lengua del siglo XVI, Juan López de Velasco, contiene a partir de la página 315 una "Tabla o índice alphabético de las palabras castellanas de dudosa ortographía" que es conveniente tener en cuenta, puesto que recoge la gran cantidad de voces que ha ido introduciendo a lo largo de la obra. Así, a propósito de la ' $b$ ' dice: 'Las palabras que tienen ' $b$ ' de la lengua Latina, de donde son tomadas las más de las que lo tienen en el Castellano son: abbad, abbadía, abbadessa, de abbate y los deduzidos dél: abbadengo y abadejo..." (pág. 35). El texto entero es una constante referencia a voces castellanas que luego se repiten en la Tabla o indice alphabético, razón por la que me ha parecido conveniente tenerla en cuenta.

Finalmente quisiera recordar que ochenta años después de que Fray Pedro de Alcalá publicase su rico y extenso Vocabulista arábigo en lengua castellana (Granada, 1505), sobre el modelo nebrisense, otro arabista, Francisco López Tamarid, con notable prestigio en su época, como demuestra el hecho de haber sido utilizado repetidamente por Covarrubias, publica, también en Granada, un Compendio de algunos vocablos arábigos introducidos en lengua castellana. Según el texto de la edición de 1585 que manejo, se trata de 503 voces $^{49}$, además de 8 Nombres arábigos usados en el Reino de

\footnotetext{
${ }^{47}$ Obras de Garcilaso de la Vega con anotaciones de Fernando de Herrera, Alonso de la Barrera, Sevilla, 1580. De esta obra realizó Antonio Gallego Morell una edición facsímil, Madrid, C.S.I.C., 1973, que es la que sigo. Recientemente, se ha vuelto a reproducir otro facsímil, Sevilla, Universidad de Sevilla, 1998.

48 Juan López de Velasco, Orthographía y pronunciación castellana, Burgos, 1582 $(\mathrm{R} / 10756)$. Este ejemplar esta encuadernado junto con la Declaración de las bozes de Benito Ruiz, fuera de consulta por deterioro. Véase $\mathrm{R}$ micro/1212.

${ }^{49}$ Francisco López Tamarid: Compendio de algvnos vocablos arabigos introdvzidos en la lengua Castellana [...]. Granada, 1585.-V. El listado de voces de López Tamarid fue añadido al final de la edición granadina (Casa de Antonio de Nebrissa, 1585) del Vocabulario con esta justificación: “... para hazer le [se refiere al Vocabulario] más uniuersal y prouechoso" y tras haber discutido los vocablos en cuestión "con muchos hombres insignes y de mucha erudición en lenguas". Tanto esta edición como la que se encuentra también junto con el texto de Nebrija, en 1589, presentan pequeñas diferencias respecto a la recopilación que del listado de López Tamarid hizo Mayans y Siscar en el tomo II de sus Orígenes (1737), donde aparece hibrero por hobero, hospa por haspa, y otras variantes sin importancia.
} 
Murcia y 9 Nombres arábigos usados en Portugal. Muchas de las voces registradas carecen de definición y en otros casos la entrada sirve de justificación para comentarios no estrictamente lexicográficos, con lo que la lista de López Tamarid se convierte casi en puro registro de voces, a pesar de lo cual me parece interesante su testimonio.

Entre las recopilaciones del léxico marítimo hay una tercera, muy pobre por cierto, que es la realizada por el cosmógrafo vizcaíno Andrés de Poza ${ }^{50}$ al comienzo del libro segundo de su Hydrografia, donde encontramos el siguiente aviso al lector: "No te admires, amigo lector, de algunos vocablos extraordinarios de que vsamos en esta segunda parte. Porque, como todas las demás professiones, así también esta de Pilotage tiene recebido su particular término y modo de hablar y entenderse, pero a esto se satisfaze con la declaración que ponemos de los vocablos que son tales". Y aparecen a continuación un total de 22 voces con sus correspondientes explicaciones. Conviene no olvidar que este es el primer glosario o repertorio impreso, lo que no deja de ser sorprendente, dado lo tardío de la fecha, 1585, y el hecho de ser tan pobre y aparecer como algo marginal, esto es, como aclaración de algunas voces de dudosa interpretación dentro de otro texto. Tampoco en este caso se encuentra vinculación alguna del repertorio léxico aquí registrado con los que aparecen en los manuscritos de A. Chaves y J. de Moya, antes mencionados.

A la breve nómina de Poza le sigue, dos años más tarde, la Instrvción návthica para el bven vso y regimiento de las naos, del montañés ${ }^{51}$ Diego García de Palacio, hombre de estirpe marinera, del Colegio de Su Majestad y Oidor, primero de la Audiencia de Guatemala y más tarde de la de México. Fue editada en México, en las prensas de Pedro Ocharte, en 1587 y puede decirse, en sentido estricto, que es el primer repertorio de léxico náutico ${ }^{52}$.

Es importante señalar que la obra de García de Palacio se adelanta a cualquier otro tratado de construcción náutica europeo y ello es reflejo de la importancia que habían experimentado las atarazanas en Nueva España. En muchos aspectos, la Instrvción návthica enlaza con otra obra del propio autor, los Diálogos militares, no sólo por la forma de conversación o diá-

${ }^{50}$ Andrés de Poza nació en Lendoño de Abajo (Vizcaya) y murió en Madrid el 18 de julio de 1595. Fue padre del conocido jesuita Juan Bautista Poza. Se licenció en leyes en Salamanca en 1570. Preocupado por las matemáticas, astronomía y náutica, ejerció como catedrático de la Escuela Náutica de San Sebastián. Su Hydrografia, Bilbao, 1585, fue reeditada con adiciones de Máriz Carnero en 1675.

${ }^{51}$ Pequeños datos biográficos de este autor pueden encontrarse en la introducción que Julio F. Guillén hizo para la edición facsímil de los Diálogos Militares (México, 1583) hecha por Ediciones Cultura Hispánica, Madrid, 1944.

${ }^{52} \mathrm{La}$ Instrucción náutica para navegar (con este título) ha sido editada en facsímil por Julio F. Guillén, Madrid, Ediciones Cultura Hispánica, 1944. Es esta la edición que sigo. 
logo en que se desarrolla, entre el vizcaíno curioso y el montañés sabihondo, personajes que ya habían aparecido en los Diálogos militares, sino por las remisiones internas que encontramos. Así, en el folio $111 \mathrm{r}$ de la primera, dice al referirse a las cualidades del capitán: "y porque delas calidades, sufficiencia y costumbres tengo dicho en el primer libro delos Diálogos Militares (que poco ha salieron a luz), lo que basta para exercitarse bien en qualquier acto de guerra, assí de mar como de tierra, sólo diré en este lugar lo que conviene llevando vna nao de merchandía...".

La obra consta de cuatro libros, al final de los cuales aparece un vocabulario. Los tres primeros libros se dedican al arte de navegar, con exposición de las tablas de declinación, regimientos del astrolabio, nordestear y noroestear de la aguja, en el primero, cálculo de la hora de pleamar y de los pronósticos del tiempo, así como de la construcción de la carta de marear, entre otros temas, en el libro segundo y tercero, para darnos en los primeros capítulos del cuarto un verdadero tratado de construcción naval, así como información precisa de la maniobra de arboladura y velamen. Siguen luego una serie de cuestiones sobre pertrechos y descripción de los oficios de abordo, desde capitán a paje, para acabar con un Vocabulario de los nombres que usa la gente dela mar en todo lo que pertenece a su arte, por orden alphabético. Se trata de un glosario de 505 entradas, marcadas como tales, que tiene una extraordinaria importancia para la historia de la lexicografía marítima española, porque marca el punto de partida de cualquier estudio filogenético que, dicho sea de paso, aunque haya algunas coincidencias lemáticas, el vocabulario de D. G. ${ }^{a}$ de Palacio es totalmente independiente de los anteriores en el tiempo.

Las Reglas gramaticales de Antonio del Corro, primer texto de enseñanza gramatical del español impreso en Inglaterra, se tradujeron al inglés en 1590 por un amigo del autor español, John Thorius ${ }^{53}$, quien añadió al final un diccionario de todas las palabras españolas que se usan en los ejemplos de esta gramática, así como otras muchas voces muy frecuentes. El repertorio en verdad no era tan grande, puesto que se reduce a unas 850 voces.

Es mucho más interesante la Bibliotheca Hispanica ${ }^{54}$ de Richard Percivale, texto editado un año más tarde. La obra, como se indica en el título,

${ }^{53}$ The Spanish Grammer: With certeine Rules teaching both the Spanish and French tongues. By which they that haue some knowledge in the French tongue, may the easier attaine to the Spanish, and likewise they that haue the Spanish, with more facilitie learne the French: and they that are acquainted with neither of them, learne either or both. Made in Spanish, by $M$. Anthonie de Corro. With a Dictionarie adioyned vnto it, of all the Spanish wordes cited in this Booke: and other more wordes most necessarie for all such as de sire the knowledge of the same tongue, Iohn Wolfe, Londres, 1590. Ejemplar R/23627 de la Biblioteca Nacional de Madrid.

${ }^{54}$ Richard Percivale, Bibliotheca Hispanica. Containing a Grammar, with a Dictionarie in Spanish, English, and Latine, gathered out of diuers good Authors: very profitable for the studious of the Spanish toong, by Iohn Iackson, for Richard Watkins, Londres, 1591. 
está dividida en dos partes (gramática y diccionario) con portadas diferentes, aunque bajo el título común de Bibliotheca Hispanica. El diccionario es la parte más extensa, con aproximadamente 13.000 voces $\mathrm{y}$, por lo mismo, es el primer repertorio amplio español-inglés. De él partirá John Minsheu y la lexicografia hispanoinglesa posterior.

También en 1591, el profesor de español William Stepney publica su famoso The Spanish Schoole-master ${ }^{55}$. El texto, como se señala en el título, contiene un diálogo para cada día de la semana, refranes y sentencias, así como el Padrenuestro, los artículos de la fe, y un "vocabulario con otras diversas cosas para el conocimiento de la lengua". La estructura de la obra lleva directamente a la línea de Berlaimont y más en concreto al Dictionnaire des huit langues, publicado en Amberes en 1558. El vocabulario ocupa las págs. 184 a 252 , con un total aproximado de 17.000 voces, agrupadas en 22 secciones: De la tierra, montañas, valles; de los oficiales y sus instrumentos; de todas las partes del cuerpo humano, etc. No recoge, sin embargo, la totalidad del léxico empleado con anterioridad a lo largo de la obra, lo que da al Vocabulario un carácter independiente con relación al resto de la obra.

La última recopilación que dentro del siglo XVI tengo documentada es la que se encuentra a partir de la pág. 67 del Libro mvy vtil y provechoso para aprender la Latinidad $^{56}$ de Miguel Navarro. El repertorio en cuestión, "Vocabvlario de las partes exteriores y interiores del cuerpo» ocupa hasta la pág. 221 y es un vocabulario temático, como tantos de la época, que tiene, sin embargo, no pocas incongruencias como el hecho de recoger en el epígrafe dedicado a las partes del cuerpo, voces que pertenecen a otros ámbitos designativos. El texto se presenta a dos columnas, con el latín a la izquierda, puesto que la obra está pensada desde el latín, y a pesar de los pequeños problemas que la nómina plantea, me parece importante tenerla en cuenta por su riqueza léxica, 2.399 voces.

55 Containing seven Dialogues [...] Whereunto, besides seuen Dialogues, are annexed most fine Prouerbs and sentences, as also the Lords prayer, the Articles of our beliefe, the ten Commandements, and a Vocabularie, with diuers other things necessarie to be knowne in the said tongue. Newly collected and set forth by W. Stepney, professor of the said tongue in the famous Citie of London, R. Field for Iohn Harison, Londres, 1591.

${ }^{56}$ Miguel Navarro, Libro mvy v́til y provechoso para aprender la Latinidad, en el qual se pone en prática [sic] el modo de construir los Autores, con vn vocabulario de las partes exteriores y interiores del hombre, Madrid, Imprenta Real, 1599. Aunque en la portada puede leerse la fecha de MDCXIX, la fecha real, como figura en el colofón, es la de MDXCIX, sin duda, debida a un cambio de las letras XC. También en el colofón se dice que el impresor es Juan de Flandes. La primera edición de esta obra resulta muy rara: no está en la Biblioteca Nacional de Madrid, y se cita un ejemplar falto de portada en la Biblioteca de la Facultad de Filosofía y Letras de la Universidad Complutense de Madrid con el que no hemos podido dar, por lo que manejamos una fotocopia del de la biblioteca particular de don Bernard Pottier, a quien agradecemos su generosidad. 
No quisiera acabar sin referirme a una obra importante, esta sí de lexicografía estricta, con la que se cierra el siglo. Se trata del $A$ Dictionarie in Spanish and English ${ }^{57}$, de John Minsheu, la obra más extensa de cuantas se publicaron hasta la fecha. Consta de dos partes, la segunda inglés-español y tiene, además, una colección de refranes, diálogos y un glosario de palabras procedentes del árabe. De las aproximadamente 21.000 voces que la integran, algo más de la mitad (aproximadamente 12.500) proceden de la obra de R. Percivale, hecho que justifica el título. Pero entiendo que los grandes diccionarios, aun los bilingües, son preocupación que excede a los límites que me he autoimpuesto.

57 J. Minsheu, A Dictionarie in Spanish and English, first published into the English tongue by Ric. Perciuale [...] Hereunto for the further profite and pleasure of the learner or delighted this tongue, is annexed an ample English Dictionarie [...], Edm. Bollifant, Londres, 1599. Ejemplar de la Biblioteca Nacional de Madrid, 3/45017. El texto fue reeditado en 1623. Entre ambas fechas Minsheu publicó (empieza el título en griego) Ductor in Linguas, The Gvide Into tongves. Cum illarum harmonia, and Etymologijs, Originationibus, Rationibus, and Deriuationibus in omnibus his vndecim Linguis, viz: 1. Anglica. 2. Cambro-Britanica. 3 Belgica. 4. Germanica. 5. Gallica. 6. Itallica. 7. Hispanica. 8. Lusitanica seu Portugallica. 9. Latina. 10. Graeca. 11. Hebrea, \&c. [...] Sigue el título en inglés. John Minsheu, Londres, 1617. Manejo el ejemplar de la Bibliothèque Nationale de París, X-660; hay otro ejemplar en la Biblioteca Nacional de Madrid, 2/62387. El Ductor in linguas consta de dos partes: Ductor in linguas, en once lenguas, y un Vocabvlarivm Hispanicolatinvm et Anglicum copiosissimum [...] con portada propia, aunque sin lugar ni fecha. El propio autor afirma que su Vocabvlarivm Hispanicolatinvm et Anglicum, es el diccionario etimológico más copioso impreso hasta la fecha. 